\title{
Correlation Between Serum Procollagen Type 1 N-Terminal Propeptide Level With Modified Rodnan Skin Score In Systemic Sclerosis Patients.
}

\author{
Vincent $^{1}$, Sumartini Dewi ${ }^{2}$ Rachmat Gunadi Wachjudi²
}

'Department of Internal
Medicine,
'Division of
Rheumatology
Faculty of Medicine
Universitas
Padjadjaran/ Hasan
Sadikin General
Hospital Bandung
Corespondence:
Vincent, MD
email: vincent.lim.86@
gmail.com

'Departm
Medicine,

${ }^{2}$ Division of

Rheumatology

Faculty of Medicine

Sadikin General

gmail.com

\begin{abstract}
Introduction: Systemic Sclerosis (SSc) is a chronic autoimmune disease, characterized by vasculopathy, specific autoimmune, and fibrosis. Assesment of skin fibrosis by modified Rodnan Skin Score (mRSS) can not detect the minimal changes of skin fibrosis within less than 3 months. A biomarker is needed to assess the minimal changes of skin fibrosis progressivity with a more objective, quantitative, and rapid way. Procollagen type-1 N-Terminal Propeptide (P1NP), a degradation product of collagen type-1, may become a potential biomarker for skin fibrosis. This study aims to evaluate the correlation between skin fibrosis by mRSS with P1NP serum in systemic sclerosis.
\end{abstract}

Methods: This was a cross-sectional study performed among systemic sclerosis patients at Rheumatology outpatient clinic, Dr.Hasan Sadikin Hospital Bandung, from May 2016 to July 2016. Skin fibrosis was measured by mRSS. P1NP level was determined by ELISA. Data were analyzed using Rank-Spearman Correlation.

Result: There were thirty-seven subjects, with mean age 37 (SD \pm 7 ) years old. Most of subjects were female (91.9\%). Subjects consisted of $23(62.2 \%)$ limited SSc and 14 (37.8\%) diffuse SSc. Six subjects (16.2\%) were DMARD naïve. We found median (range) P1NP serum was 43.85 (9.81-127.90) ng/dL, while the median of MRSS was 14 (3-36). There is a moderate correlation between MRSS and P1NP serum ( $r=0.443, p=0.003)$

Conclusion: There was a significant correlation between mRSS and P1NP serum in systemic sclerosis patient at Dr. Hasan Sadikin Hospital Bandung.

Keywords: systemic sclerosis, P1NP, modified rodnan skin score.

\section{Introduction}

Systemic Sclerosis is an autoimmune disease involving many organs with complex pathophysiology and heterogenous clinical features. The exact etiology of systemic sclerosis remains unknown to this day. The disease severity and prognosis are varied among the patients, depending on the involvement of organs in the disease. ${ }^{1-3}$

Hasan Sadikin General Hospital Rheumatology
Clinic data revealed some alterations of disease patterns prior to JKN (Jaminan Kesehatan Nasional, National Health Insurance) enactment in 2014 compared to the period after the JKN enactment. Connective tissue diseases had the largest portion of diseases in 2013 and 2014 at Rheumatology Clinic, the number rose from $51.2 \%$ in 2013 to $63.5 \%$ in 2014. ${ }^{4,5}$ Systemic Sclerosis was the third most common disease in our Rheumatology Clinic, the number of the cases rose from 189 patients/year in 2013 to 196 patients/year in 2014. Numerous study reported that survival rate of the disease has not significantly been improved since the last 30 years. While the opposite result was reported by some other studies, such as Steen, et al study reported the increase of 10-year survival rate of systemic

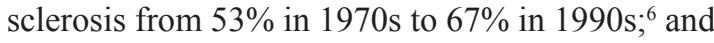
Ehai, et al study revealed the improvement of the mortality rate of systemic sclerosis patients for the last 40 years. ${ }^{7,8}$

Modified Rodnan Skin Score (MRSS) is well correlated with the gold standard assessment, skin biopsy, for skin fibrosis in systemic sclerosis disease. However, performing MRSS assesment requires great skills. Moreover, even though it is well corelated with the gold standard, MRSS is not sensitive to detect the small skin alteration happened within the development of the disease. ${ }^{1,9}$ Therefore, some biologic markers are necessary used to assist clinicians to examine skin fibrosis because it is reported more objectively, quantitatively, and rapidly in detecting small skin lession in fibrosis skin . ${ }^{10}$

Procollagen Type-1 Terminal Propeptide (P1NP), degraded product from type-1 collagen synthesis, is one of the potential biological marker. Nevertheless, some studies which has investigated the association between skin fibrosis severity assessed by MRSS with the level of serum P1NP in systemic sclerosis patients, revealed inhomogenous results. ${ }^{11,12,13}$ Further, there is not any study examining association between concentration of serum P1NP of any disease progressivity, particularly skin fibrosis severity according to 
MRSS, has ever been conducted in Indonesia. Therefore, the study is perform to seek any positive correlation between the P1NP level and skin fibrosis severity based on MRSS in systemic sclerosis patients. Hopefully P1NP will be able to be a biologic marker

\section{Methods}

Subject

Subject were chosen from Hasan Sadikin General Hosipital's outpatient clinic and ward who came from may to July 2016 with consecutive random sampling methods. Samples included in this study with criteria: age between 18 to 50 years old ${ }^{4,14,15}$ and has been diagnosed as Systemic Sclerosis using ACR/EULAR 2013 criteria. Subject were excluded if they have some comorbidities, such as osteoporosis ${ }^{16}$, hepatic cirrhosis $^{17}$, bone metastases malignancy disease ${ }^{18}$, post menopause woman ${ }^{19}$, and chronic kidney disease ${ }^{20}$

Subjects were screened for any one of those exclusion criteria: osteoporosis, hepatic cirrhosis, bone metastase, menopausal status, and chronic kidney disease. Osteoporosis were diagnosed if Bone Mineral Densitometry (BMD) T score $<-2.5$, diagnosed as osteoporosis in medical history, or using moderate dose steroid therapy $(\geq 7,5 \mathrm{mg}$ prednisone/day) for more than 3 months with $\mathrm{T}$ score $<1.5$. Hepatic Cirrhosis were diagnosed if there is clinical stigmata of chronic hepatic disease or diagnosed as cirrhosis in medical records. Bone metastasis were assesed by medical record history of malignancy and bone metastases. Menopause status reffered for this study is when mensturation cycle has been stop for 12 months or more. Chronic kidney disease reffered for this study is when estimated Glomerular Filtration Rate (eGFR) $<60 \mathrm{ml} / \mathrm{min} / 1.73 \mathrm{~m}^{2}$ counted using The Modification of Diet in Renal Disease (MDRD) or has been diagnosed as chronic kidney disease in medical records.

\section{MRSS Examination}

MRSS examination were done by selected rheumatology consultant. All Hasan Sadikin General Hospital/Padjajaran University rheumatology consultants were included for "interobserver variability agreement" assesment. Physician who has good intraclass correlation coefficient result $(>0.7)$ were selected to be the examinee for our study.

MRSS examination is used to classified skin fibrosis. Skin fibrosis were assesed in 17 area of the skin, each area will be scored from 0 to 3 . Score ' 0 ' means normal skin, ' 1 ' means minimal skin thickening, ' 2 ' means moderate skin thickening,' 3 ' means severe skin thickening where the skin has been fixated with the deeper tissue.

\section{P1NP concentration}

The concentration of serum P1NPwere assesed stimultaneously with MRSS examination. Using ELISA sandwich methods. The result were served in $\mathrm{ng} / \mathrm{mL}$.

\section{Statistical Analysis}

Data were analyzed using SPSS version 17.0. Normality of the quantitative data were test using Shapiro-Wilk test. We used two analysis methods, such as univariate and bivariate analysis methods. Pearson correlation test were used to assess any correlation in normal distribution data and Rank Spearman correlation test were used to assess any correlation in not normal distribution data.

\section{Result}

From May to July 2016, we found 40 patients fulfilled the inclusion criteria. Three of them were excluded due to osteoporosis which is found during the first assesment. Within thirty seven subjects, there were 14 subjects $(37,8 \%)$ with diffuse systemic sclerosis and 23 subjects $(62,2 \%)$ with limited systemic sclerosis. Six subjects (16.2\%) were newly diagnosed systemic sclerosis patients who have never gotten methotrexate therapy. The median for disease course were 26 months, ranged from 6 months to 8 years.

Table 1. Subject Characteristics

\begin{tabular}{lc}
\hline Characteristics & Result \\
\hline Age (years) & $37 \pm 7$ years \\
Female & $34(91,9 \%)$ \\
Systemic Sclerosis Type & \\
$\quad$ Limited, N(\%) & $23(62,2 \%)$ \\
$\quad$ Diffuse, N(\%) & $14(37,8 \%)$ \\
Course of Disease (Month) & $26(6-96)$ month \\
Medication History, N(\%) & \\
$\quad$ Methotrexate & $31(83,8 \%)$ \\
$\quad$ Steroids & $27(73,0 \%)$ \\
$\quad$ Cyclophosphamide & $1(2,7 \%)$ \\
CCB & $31(83,8 \%)$ \\
$\quad$ Aspirins & $29(78,4 \%)$ \\
Clinical Features of ACR EULAR 2013, N(\%) & \\
Finger Fibrosis & $37(100 \%)$ \\
Finger Oedema & $24(64,9 \%)$ \\
Finger Scar & $26(70,3 \%)$ \\
Telangiectasia & $13(35,1 \%)$ \\
Salt and Pepper Appearance & $21(56,8 \%)$ \\
Raynaud Phenomenon & $33(89,2 \%)$ \\
MRSS (score) & $14(3-31)$ \\
\hline
\end{tabular}

CCB: Calcium Channel Blocker

Subjects were diagnosed as sclerosis systemic prior to this study. Among the subjects, 31 subjects $(83.8 \%)$ had been treated with methotrexate. Steroids were given to 27 (73.0\%) subjects with equivalent dose less than $7.5 \mathrm{mg}$ of prednisone a day (mean $5 \mathrm{mg}$ of prednisone). One subject $(2.7 \%)$ had undergone cyclophosphamide therapy due to lung involvement, while calcium channel blockers were given to 31 (89.2\%) subject for treating Raynaud phenomenon.

Finger fibrosis was the most common manifestation, found in all subjects, followed by Raynaud phenomenon (33 subjects or $89.2 \%$ of total subjects), finger ulcers or scars (26 subjects or $70.3 \%$ of total subjects), finger oedema (24 subjects or $64.9 \%$ of total subjects), salt and pepper appearance (21 subjects or 
$56.8 \%$ of total subjects), and telangiectasia (13 subjects or $35.1 \%$ of total subjects).

Table 2 explained the subjects' laboratory features. All hematologic parameter averages were within normal limits. This examination was also conducted over the entire subjects for detecting any exclusion criteria, such as: hepatic cirrhosis, post-menopause, bone-metastasized malignancies, chronic kidney disease and osteoporosis.

Table 2. Laboratory Features

\begin{tabular}{lc}
\hline Characteristics (unit) & Result \\
\hline Laboratory features & $12,9 \pm 1,2$ \\
$\mathrm{Hb}(\mathrm{g} / \mathrm{dL})$ & $8,200(4,490-19,400)$ \\
Leukocytes $\left(/ \mathrm{mm}^{3}\right)$ & $312,703 \pm 91,743$ \\
Trombocytes $\left(/ \mathrm{mm}^{3}\right)$ & $28(6-87)$ \\
ESR $(\mathrm{mm} / \mathrm{h})$ & $17(11-59)$ \\
SGOT (U/L) & $13(5-39)$ \\
SGPT (U/L) & $0,65 \pm 0,15$ \\
Creatinine $(\mathrm{mg} / \mathrm{dL})$ & $0(0 \%)$ \\
Proteinuria, $\mathrm{n} \mathrm{( \% )}$ & $43,85(9,81-127,90)$ \\
P1NP $(\mathrm{ng} / \mathrm{mL})$ &
\end{tabular}

Bivariate analysis was carried out to test the significancy association of P1NP level and MRSS. The result of rank spearman correlation test was presented in table 3

Table 3. MRSS Bivariate Test Result of Serum P1NP

\begin{tabular}{lcc}
\hline \multirow{2}{*}{ Variable } & \multicolumn{2}{c}{ MRSS } \\
\cline { 2 - 3 } & $\mathrm{R}$ & $p$-value \\
\hline $\mathrm{P} 1 \mathrm{NP}(\mathrm{ng} / \mathrm{dL})$ & 0,443 & $0,003^{*}$ \\
\hline
\end{tabular}

NB: Rank spearman analysis was used for analysis, the resilf was significant if $p<0.05$

Bivariate test revealed a significant correlation between skin fibrosis severity assessed by MRSS and serum P1NP level $(p<0.05)$ as shown in Table 3 . The correlation was categorized as medium correlation according to Guilford criteria with $r$ ranged from 0.40 to 0.70 . The scattered diagram of Correlation Between MRSS and Serum P1NP is presented in Figure 1.

\section{Figure 1 Scatter Diagram Revealing Correlation} Between MRSS and Serum P1NP

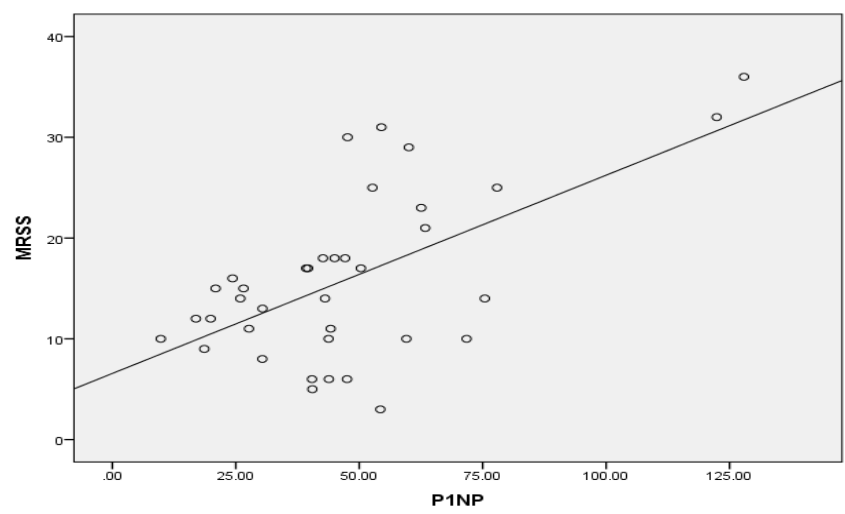

\section{Discussion}

Mean age of subjects involved in this study was $37 \pm 7$ years old, explaining that the highest prevalence of systemic sclerosis onset was between third and fourth decade..$^{21,22}$ The epidemiology of SSc in our studies is dissimilar with Denton, et al study which found the mean age of subjects $48.5 \pm 11$ years old, but it is consistent with Pagalavan, et al study in Malaysia which found the mean age 38.8 years old. The wide difference between the two studies might be happened due to the different race of the subjects involved. The races difference will also contribute to the expression of autoantibody and other genetical factors that influence systemic sclerosis pathophysiology between Caucasians and Asians. ${ }^{23-25}$ Female constituted for $91.9 \%$ of subjects involved in this study. It is concordant with the fact that systemic sclerosis mostly affects women. ${ }^{21,26} \mathrm{~A}$ study was conducted by Low, et al. in Asia also revealed $86 \%$ of systemic sclerosis patients were women. ${ }^{27}$

All subjects in this study was diagnosed using first criteria, which was skin thickening at fingers of both hands that expanded proximally to metacarpophalangeal joints. That first criteria was fundamentally similar to major criteria on ACR 1980 which means the inclusion criteria of this study was similar to the two studies mentioned before. Raynaud phenomenon was found in $89.2 \%$ of this study's subjects. The phenomenon is, in fact, common at the early stage of disease. ${ }^{26,28}$ Other clinical findings such as finger scars or ulcers $(70.3 \%$ of the subjects) and telangiectasia (35.1\% of the subjects) was considerably resemble to ones revealed by Low, et al., with Raynaud phenomenon, finger scars or ulcers, and telangiectasia were found in $80.5 \%, 70.5 \%$, and $34.5 \%$ of the subjects, respectively. ${ }^{29}$

The median for MRSS in this study was 14 , ranged between 3 to 36 . There was a significant difference $(p=0.005)$ between the result of MRSS in type diffuse and limited systemic sclerosis. As gold standard examination for assessing fibrosis severity, MRSS could be helpful in measuring the course of disease and skin fibrosis response to therapy. MRSS monitoring, based on disease development conducted in a longitudinal study, revealed the changing score after 3-6 month of therapy administration. ${ }^{30-32}$ The proximal parts of the body may return to normal during the therapy, except the part which suffered severe fibrosis or atrophy, frequently in the distal part of the finger. ${ }^{33}$

The median level of P1NP serum was 43.85 (9.8-127.90) $\mathrm{ng} / \mathrm{ml}$. Minier, et al. study showed nearly same result, 45.0 (34-65) ng/ml..$^{34}$ The median level of P1NP serum in our study was higher than the median level of P1NP serum in non SSc patients which presented by Minier, et al study, 33.5 (28.344.5) $\mathrm{ng} / \mathrm{ml} .{ }^{34}$

Bivariate analysis of skin fibrosis assessed by MRSS yielded a significant correlation with the level of P1NP serum ( $r=0.443 ; \mathrm{p}=0.003)$. The result was consider high if we compare it to the result revealed by Denton, et al. $(\mathrm{r}=0.37$; $\mathrm{p}=0.027$ ). However both studies show a significant correlation $(p<0.05)$ between the two variables. 
Our study supported the fact that P1NP has a role on fibrosis process. P1NP is released to the circulation as a metabolite in collagen syntesis process, a fundamental process of fibrosis. ${ }^{21,35,36}$ A study conducted by Minier, et al. disclosed a significant correlation between MRSS and P1NP compared to other biologic markers. ${ }^{37} \mathrm{~A}$ study carried out by Denton, et al. showed a consistent result with the previous two studies, that P1NP does not only have positive correlation with MRSS ( $r=037, p=0.027$ ), but also can be used as marker in monitoring the response of therapy. ${ }^{11} \mathrm{P} 1 \mathrm{NP}$ was stated as one of the excellent biologic marker for fibrosis process according to Panticos, et al. They revealed the presence of excessive deposition of type 1 collagen in skin biopsy of systemic sclerosis patients. ${ }^{38}$

We realized some limitation of our study that could influence the results of our study. First, the limitation number of the samples due to low prevalence of systemic sclerosis in our center. A multicenter study is needed to gather a higher number of subjects. Second, the method used in this study could not be used to describe the real picture regarding to the correlation between P1NP and MRSS.

\section{Conclusion}

There was a medium and significant correlation between skin fibrosis severity assessed by MRSS and the concentration of P1NP serum in systemic sclerosis patients. Further study assessing the correlation between skin fibrosis severity based on MRSS and serum P1NP concentration between newly diagnosed patients who never got methotrexate and steroid using a cohort method are needed in order to reveal the correlation of P1NP level in monitoring the therapy response and prove the role of P1NP as a potential marker for SSc's disease activity.

The measurement of P1NP serum could be considered as a routine examination that would assist clinicians to assess skin fibrosis severity in systemic sclerosis patients.

\section{References}

1. Mayes M, Assasi S. Classification and Epidemiology of scleroderma. In: Hochberg MC, Silman AJ, Smolen JS, Weinblatt ME, Weisman MH, editor. Rheumatology (Oxford). Edisi ke-6. Philadelphia: Elsevier; 2015: p.1153-7.

2. Abraham DJ, Krieg T, Distler J, Distler O. Overview of pathogenesis of systemic sclerosis. Rheumatology (Oxford). 2009;48 (Suppl 3):3-7.

3. Haustein UF. Systemic Sclerosis - An Update. Lab Med. 2011;42(9):56272.

4. Walker JG, Fritzler MJ. Systemic Sclerosis. Dalam: Shoenfeld Y, R. C, Gershwin ME, editor. Diagnostic Criteria in Autoimune Diseases. New York: Humana press; 2008:31.

5. Mulasimadhi K, Wachjudi RG, Rahmadi AR. Perubahan Pola Penyakit Pasien Di Klinik Reumatologi RSUP Dr. Hasan Sadikin Sebelum dan Sesudah Era Jaminan Kesehatan Nasional [Skripsi]. Divisi Rumatologi, Departemen IImu Penyakit Dalam Fakultas Kedokteran Universitas Padjajaran;2015.

6. Steen VD, Medsger TA. Changes in causes of death in systemic sclerosis, 1972-2002. Ann Rheum Dis. 2007;66(7):940-4.
7. Doria A, laccarino L, Ghirardello A, Zampieri S, Arienti S, Sarzi-Puttini $P$, et al. Long-term prognosis and causes of death in systemic lupus erythematosus. Am J Med. 2006;119(8):700-6.

8. Elhai M, Meune C, Avouac J, Kahan A, Allanore Y. Trends in mortality in patients with systemic sclerosis over 40 years: a systematic review and meta-analysis of cohort studies. Rheumatology (0xford). 2012;51 (6):1017-26.

9. Czirjak L, Foeldvari I, Muller-Ladner U. Skin involvement in systemic sclerosis. Rheumatology (Oxford). 2008;47 (Suppl 5):44-5.

10. Czirjak L, Nagy Z, Aringer M, Riemekasten G, Matucci-Cerinic M, Furst DE. The EUSTAR model for teaching and implementing the modified Rodnan skin score in systemic sclerosis. Ann Rheum Dis. 2007;66(7):966-9.

11. Denton CP, Merkel PA, Furst DE, Khanna D, Emery P, Hsu VM, et al. Recombinant human anti-transforming growth factor beta1 antibody therapy in systemic sclerosis: a multicenter, randomized, placebocontrolled phase I/II trial of CAT-192. Arthritis Rheum. 2007;56(1):32333.

12. Moinzadeh P, Denton C, Abraham D, Ong V, Hunzelmann N, Eckes B, et al. Biomarkers for skin involvement and fibrotic activity in scleroderma. J Eur Acad Dermatol Venereol. 2012;26(3):267-76.

13. Scheja A, Wildt M, Wollheim FA, Åkesson A, Saxne T. Circulating collagen metabolites in systemic sclerosis. Differences between limited and diffuse form and relationship with pulmonary involvement. Rheumatology (Oxford). 2000;39(10):1110-3.

14. Denton C, Black C, Korn J, De Crombrugghe B. Systemic sclerosis: current pathogenetic concepts and future prospects for targeted therapy. The Lancet. 1996;347(9013):1453-8

15. Khosla S, Riggs BL. Pathophysiology of age-related bone loss and osteoporosis. Endocrinol Metab Clin North Am. 2005;34(4):1015-30.

16. Lee J, Vasikaran S. Current Recommendations for Laboratory Testing and Use of Bone Turnover Markers in Management of Osteoporosis. Ann Lab Med. 2012;32(2):105-12

17. Borlaug BA, Paulus WJ. Heart failure with preserved ejection fraction: pathophysiology, diagnosis, and treatment. Eur Heart J. 2011;32(6):6709.

18. Dean-Colomb W, Hess KR, Young E, Gornet TG, Handy BC, Moulder SL, et al. Elevated serum P1NP predicts development of bone metastasis and survival in early-stage breast cancer. Breast Cancer Res Treat. 2013;137(2):631-6

19. Kucukalic-Selimovic E, Valjevac A, Hadzovic-Dzuvo A. The utility of procollagen type $1 \mathrm{~N}$-terminal propeptide for the bone status assessment in postmenopausal women. Bosn J Basic Med Sci. 2013;13(4):259-65

20. Cavalier E, Lukas P, Carlisi A, Gadisseur R, Delanaye P. Aminoterminal propeptide of type I procollagen (PINP) in chronic kidney disease patients: the assay matters. Clin Chim Acta. 2013;425:117-8

21. Varga J. Systemic sclerosis: epidemiology, pathology and pathogenesis. Primer on rheumatic diseases 13th ed Atlanta: Springer. 2008:351-8.

22. Denton C, Black C, Korn J, De Crombrugghe B. Systemic sclerosis: current pathogenetic concepts and future prospects for targeted therapy. The Lancet. 1996;347(9013):1453-8.

23. Arnett FC, Gourh P, Shete S, Ahn CW, Honey R, Agarwal SK, et al. Major Histocompatibility Complex (MHC) class II alleles, haplotypes, and epitopes which confer susceptibility or protection in the fibrosing autoimmune disease systemic sclerosis: analyses in 1300 Caucasian, African-American and Hispanic cases and 1000 controls. Ann Rheum Dis. 2010;69(5):822-7. doi: 10.1136/ard.2009.111906

24. He D, Wang J, Yi L, Guo X, Guo S, Guo G, et al. Association of the HLA-DRB1 with Scleroderma in Chinese Population. PLoS One. 2014;9(9):e106939.

25. Pauling JD, McHugh N. The Clinical Aspects of Autoantibodies. In Scleroderma From Pathogenesis to Comprehensive Management. Varga J, Denton CP, Wigley FM, ed. New York: Springer; 2012: p.209-21.

26. Gabrielli A, Avvedimento EV, Krieg T. Scleroderma. N Engl J Med. 2009;360(19):1989-2003 
27. Ling ALH, Gee TG, Giap LW, Cheng NS, Santosa A, Chan G, et al. Disease Characteristics of the Singapore Systemic Sclerosis Cohort. Proceedings of Singapore Healthcare. 2013;22(1):8-14.

28. Mayes MD. Systemic sclerosis. In Primer on the rheumatic diseases, $13^{\text {th }}$ ed. Klippel JH, Stone JH, Crofford LeJ, White PH, ed. New York: Springer; 2008:343-62.

29. Low A, Gee TG, Giap LW, Cheng NS, Santosa A, Chan G, et al. Disease Characteristics of the Singapore Systemic Sclerosis Cohort. Proceedings of Singapore Healthcare. 2013;22(1):8-14.

30. Le EN, Wigley FM, Shah AA, Boin F, Hummers LK. Long-term experience of mycophenolate mofetil for treatment of diffuse cutaneous systemic sclerosis. Ann Rheum Dis. 2011;70(6):1104-7.

31. Kuhn A, Haust M, Ruland V, Weber R, Verde P, Felder G, et al. Effect of bosentan on skin fibrosis in patients with systemic sclerosis: a prospective, open-label, non-comparative trial. Rheumatology (Oxford). 2010;49(7):1336-45.

32. Amjadi S, Maranian P, Furst DE, Clements PJ, Wong WK, Postlethwaite $A E$, et al. Course of Modified Rodnan Skin Score in Systemic Sclerosis Clinical Trials: Analysis of 3 Large Multicenter, Randomized Clinical Trials. Arthritis Rheum. 2009;60(8):2490-8.
33. Varga J, Denton CP, Wigley FM. Scleroderma: From Pathogenesis to Comprehensive Management [ebook]. New York: Springer;2012.

34. Minier T, Nagy Z, Balint Z, Farkas H, Radics J, Kumanovics G, et al. Construct validity evaluation of the European Scleroderma Study Group activity index, and investigation of possible new disease activity markers in systemic sclerosis. Rheumatology (Oxford). 2010;49(6):1133-45.

35. Varga J. Systemic Sclerosis : Epidemiology, pathology, and Pathogenesis. In Primer on The Rheumatic Disease, $13^{\text {th }}$ edition. Klippel JH, Stone JH, Crofford LJ, White PH, editor. New York: Springer; 2008: p.351-8.

36. Beyer C, distler 0 , distler JHW. Biomarker of Fibrosis. In Scleroderma From Pathogenesis to Comprehensive Management. Varga J, Denton CP, Wigley FM, editor. London: Springer; 2012: p.283-9.

37. Minier T. Assesment of Disease Activity and Evaluation of Clinical Parameters and Biomarkers in Systemic Sclerosis. University of Pecs; 2011.

38. Ponticos M, Papaioannou I, Xu S, Holmes AM, Khan K, Denton CP, et al. Failed degradation of JunB contributes to overproduction of type I collagen and development of dermal fibrosis in patients with systemic sclerosis. Arthritis Rheumatol. 2015;67(1):243-53. 